\title{
KEANEKARAGAMAN FORAMINIFERA BENTIK DALAM SEDIMEN DASAR PERAIRAN TELUK BALIKPAPAN, KALIMANTAN TIMUR
}

\section{DIVERSITY OF BENTIC FORAMINIFERA IN SEDIMENT OF BALIKPAPAN BAY WATERS, KALIMANTAN TIMUR}

\author{
Mastuti Widianingsih ${ }^{1}$, Endang L. Widiastuti ${ }^{1}$, Kresna Tri Dewi ${ }^{2}$ \\ ${ }^{1}$ Jurusan Biologi FMIPA Universitas Lampung \\ ${ }^{2}$ Pusat Penelitian dan Pengembangan Geologi Kelautan (PPPGL), Bandung \\ e-mail : mastutiwidianingsih24@ovi.com \\ Jurusan Biologi FMIPA Universitas Lampung \\ Jl. Prof.Dr. Soemantri Brojonegoro No. 1, Bandar Lampung, Lampung, Indonesia, 35145
}

\begin{abstract}
Abstrak
Foraminifera bentik merupakan salah satu Protozoa yang dapat terawetkan dalam sedimen perairan. Organisme bersel tunggal ini telah banyak digunakan sebagai indikator lingkungan karena sangat sensitif terhadap perubahan lingkungan di sekitarnya. Penelitian ini bertujuan untuk mengetahui keanekaragaman foraminifera bentik dalam 20 sampel sedimen dasar perairan Teluk Balikpapan, Kalimantan Timur dalam kaitannya dengan beberapa parameter lingkungan air seperti kedalaman, kecerahan, temperatur, $\mathrm{pH}$, turbiditas, salinitas, dan oksigen terlarut serta pembuatan peta sebaran spasialnya. Hasil penelitian menunjukkan bahwa terdapat 3 spesies foraminifera bentik yang mendominasi yaitu Asterorotalia trispinosa (1.553 spesimen) diikuti oleh Rotalia sp.1 dan Rotalia sp.2. Jumlah spesies terbanyak didapatkan pada titik TB-05 (33 spesies) yang terletak di bagian luar teluk Balikpapan. Indeks Keanekaragaman bervariasi dari 0 sampai 4. Besarnya nilai Korelasi Pearson untuk kedalaman, kecerahan, temperatur, $\mathrm{pH}$, turbiditas, salinitas, dan oksigen terlarut berturut-turut yaitu 0,$874 ; 0,962$; 0,$962 ; 0,966 ; 0,829 ; 0,966$; dan 0,968 . Nilai korelasi tersebut bervariasi dengan distribusi foraminifera bentik di daerah penelitian.
\end{abstract}

Kata kunci : Asterorotalia trispinosa, foraminifera bentik, Teluk Balikpapan

\begin{abstract}
Foraminifera bentic is a Protozoa that can be fossilised in waters sediment. This micro-bentic fossil may be used as an enviromental indicator as very sensitive to the changes of environmental factors. The purpose of the research to investigate variety of bentic foraminifera in 20 sedimennt samples of Teluk Balikpapan watersv, Kalimantan Timur in connection with several water enviroment parameters (depth, brightness, temperature, $\mathrm{pH}$, turbidity, salinity, and dissolved oxygen) and to map their spatial distribution. Results of research show that there were found 33 species foraminifera bentic with the three most dominant species namely, Asterorotalia trispinosa (1.553 specimen) followed Rotalia sp.1 and Rotalia sp.2. The values of Correlation Pearson $(r)$ for each environmental factors are respectively 0,$874 ; 0,962$; 0,$962 ; 0,966 ; 0,829 ; 0,966 ;$ and 0,968 . These value are varied with distribution in the region studied.
\end{abstract}

Keyword : Asterorotalia trispinosa, foraminifera bentic, Balikpapan bay

\section{PENDAHULUAN}

Teluk Balikpapan terletak di sebelah barat Selat Makasar yang merupakan batas antara Kabupaten Penajam Paser Utara dan Kota Balikpapan, Propinsi Kalimantan Timur. Secara umum perairan Teluk Balikpapan dipengaruhi oleh kondisi lingkungan di bagian daratan dan lautan sekitar Selat Makasar. Pengaruh dinamika kedua lingkungan tersebut secara tidak langsung akan berpe- ngaruh pada biota di Teluk Balikpapan, termasuk foraminifera.

Foraminifera merupakan organisme bersel tunggal (uniselular) yang tubuhnya tersusun atas kalsium karbonat $\left(\mathrm{CaCo}_{3}\right)$. Berdasarkan cara hidupnya, foraminifera dibagi menjadi dua, yaitu for aminifera bentik dan foraminifera planktonik. For aminifera bentik biasa dijadikan sebagai indikator kualitas suatu perairan karena sifat hidupnya 
yang menetap dan sangat sensitif terhadap perubahan lingkungan di sekitarnya.

Kehidupan foraminifera bentik dipengaruhi oleh beberapa faktor, diantaranya kedalaman, suhu, salinitas, kecerahan, $\mathrm{pH}$, dan lain-lain. Berdasarkan hasil penelitian Murray (1973) dalam Suhartini (1989) dan Susmiati (1981) dalam Suhartini (1989) dijelaskan bahwa semakin jauh dari pengaruh daratan maka jumlah jenis dan jumlah individu foraminifera bentik akan semakin bervariasi.

Tujuan penelitian ini adalah untuk mengetahui keanekaragaman foraminifera bentik yang ada dalam sedimen dan untuk mengetahui pola sebaran foraminifera bentik yang kemun-gkinan dipengaruhi oleh beberapa faktor ling-kungan perairan sekitar Teluk Balikpapan, Propinsi Kalimantan Timur seperti kedalaman, kecerahan, temperatur, $\mathrm{pH}$, turbiditas, Salinitas, dan oksigen terlarut.

\section{BAHAN dan METODE}

Seluruh tahap penelitian ini telah dilaksanakan pada bulan Juni sampai dengan Agustus 2012 di Laboratorium Mineralogi dan Mikropaleontologi, Pusat Penelitian dan Pengembangan Geologi Kelautan (PPPGL), Badan Penelitian dan Pengembangan Energi dan Sumber Daya Mineral (Balitbang ESDM), Kementrian Energi dan Sumber Daya Mineral (KESDM), Bandung.

Slide fossil diamati dengan mikroskop binokuler yang terhubungan dengan komputer yang dilengkapi dengan perangkat lunak NISTelement. 20 sampel sedimen hasil cucian (washed residu) dari kedalaman 1-20 $\mathrm{m}$ adalah hasil sampling Tim Penelitian Lingkungan dan Kebencanaan Geologi Kelautan, Pusat Penelitian dan Pengembangan Geologi Kelautan di perairan Teluk Balikpapan pada tahun 2011. Pengambilan sampel dilakukan dengan menggunakan Grap Sampler.

Proses penjentikan (picking) adalah pemisahan spesimen sebagai objek yang diinginkan (foraminifera bentik) dari organisme atau partikel lain yang terdapat dalam sampel sedimen (Pringgoprawiro dan Kapid, 1994). Pertama dilakukan penimbangan sampel sedimen. Selanjutnya sampel sedimen ditaburkan kedalam picking tray secara merata agar tidak menumpuk. Picking ini dilakukan dengan bantuan mikroskop binokuler dengan perbesaran 100x dan kuas kecil yang terlebih dulu dicelupkan kedalam air. Penjentikan dilakukan secara terus-menerus sampai didapatkan maksimal 300 spesimen. Selanjutnya satu per satu spesimen tersebut dipindahkan kedalam assemblage slide dengan komposisi setiap petak adalah 5 spesimen.

Setelah penjentikan, selanjutnya dilakukan koleksi yaitu memindahkan spesimen foraminifera bentik dari spesies yang berbeda-beda kedalam assemblage slide yang baru. Proses ini dilakukan dengan bantuan mikroskop binokuler. Tujuan dari koleksi yaitu memu-dahkan proses identifikasi dan dokumentasi.

Dokumentasi adalah proses untuk mendapat-kan foto foraminifera bentik dengan menggu-nakan mikroskop yang terhubung dengan ka-mera dan komputer serta perangkat lunak NISTelement. Penentuan nama genus dan spesies foraminifera bentik menggunakan bu-ku acuan Barker (1960), Loeblich and Tappan (1994), dan Yassini \& Jones (1995). Identifikasi dilakukan dengan mengamati ciri-ciri morfologi foraminifera bentik yang meliputi komposisi dan bentuk cangkang, bentuk dan jumlah kamar, jumlah putaran, ornamen cangkang, dan bentuk serta posisi apertura. Dalam menentukan keragaman foraminifera, maka nilai yang digunakan adalah nilai kelimpahan, indeks keanekaragaman Shannon-Weaver, indeks kemerataan, dan indeks dominansi.

Menurut Misra (1973 dalam Bakus, 1990), rumus kelimpahan sebagai berikut :

$$
\begin{aligned}
& K=\frac{\text { Jumlah Individu Suatu Jenis Pada Plot }}{\text { Berat Sampel Sedimen (gram) }} \\
& \text { KR }=\frac{\text { Kelimpahan Suatu Spesies }}{\sum \text { Kelimpahan Seluruh Spesies }}
\end{aligned}
$$

Indeks keanekaragaman dihitung berdasarkan rumus Shannon-Weaver yang telah dibuat perangkat lunaknya oleh Bakus (1990).

$$
\begin{aligned}
& H^{\prime}=-\sum \text { pi log pi } \\
& \text { pi }=\frac{\text { ni }}{N}
\end{aligned}
$$

Keterangan :

$\mathrm{H}^{\prime}=$ Indeks keanekaragaman

$\mathrm{ni}=$ Jumlah jenis ke-i

$\mathrm{N}=$ Jumlah total individu

Kriteria nilai indeksnya adalah:

1. $H<1$, artinya komunitas dalam kondisi tidak stabil.

2. $1<\mathrm{H}<3$, artinya komunitas dalam kondisi moderat.

3. $\mathrm{H}>3$, artinya komunitas dalam kondisi baik

Nilai indeks kemerataan adalah 0-1. Indeks kemerataan dihitung berdasarkan rumus Pielou (1953) dalam Bakus (1990) yaitu : 


$$
\begin{aligned}
& \mathrm{J}^{\prime}=\frac{\mathrm{H}^{\prime}\left(\log _{\mathrm{e}}\right)}{\log _{\mathrm{e}} \mathrm{S}} \\
& \text { Keterangan : } \\
& \mathrm{J}^{\prime} \quad=\text { Indeks kemerataan } \\
& \mathrm{H}^{\prime} \quad=\text { Indeks keanekaragaman } \\
& \mathrm{S} \quad=\text { Jumlah jenis/ marga }
\end{aligned}
$$

Indeks dominansi dihitung menggunakan rumus dari Simpson (1949 dalam Bakus, 1990):

$$
\begin{aligned}
& \mathrm{D}=1-\mathrm{C} \\
& \mathrm{C}=\sum p_{i}^{2}
\end{aligned}
$$

Keterangan :

$\mathrm{D}=$ Indeks dominansi

pi $=\frac{n i}{N}$

Nilai indeks dominansi adalah 0-1. Jika mendekati 1 maka ada salah satu jenis yang mendominasi. Jika mendekati 0 maka hampir tidak ada individu yang mendominasi.

Korelasi Pearson adalah rumus yang digunakan untuk mencari hubungan antara dua variabel, yaitu variabel bebas dan variabel terikat. Korelasi ini dapat digunakan untuk me-ngetahui besarnya hubungan antara indeks keanekaragaman jenis dengan parameter kualitas air yaitu kedalaman, kecerahan, tem-peratur, $\mathrm{pH}$, turbiditas, salinitas, dan oksigen terlarut (DO). Korelasi Pearson memiliki nilai $r$ terbesar 1 dan $r$ terkecil -1 .

$$
r=\frac{\sum(x-\bar{x})(y-\bar{y})}{\sqrt{\sum(x-\bar{x})^{2} \sum(y-\bar{y})^{2}}}
$$

$\mathbf{r}$ adalah korelasi antara indeks keanekaraga-man jenis dengan parameter kualitas air. Se-dangkan $\mathbf{x}$ adalah Indeks keanekaragaman $\left(\mathrm{H}^{\prime}\right)$ dan y adalah parameter kualitas air (keda-laman, kecerahan, temperatur, $\mathrm{pH}$, turbiditas, salinitas, dan DO).

Peta sebaran foraminifera dibuat berdasarkan hasil pengolahan data berupa kelimpahan, indeks keanekaragaman, indeks kemerataan, dan indeks dominansi sehingga diketahui pola sebaran masing-masing indeks.

Tabel 1. Karakteristik Penilaian Korelasi

\begin{tabular}{|c|c|}
\hline Interval & Tingkat Hubungan \\
\hline 0 & Tidak ada korelasi \\
\hline $0,01-0,20$ & Sangat rendah \\
\hline $0,21-0,40$ & Rendah \\
\hline $0,41-0,60$ & Agak rendah \\
\hline $0,61-0,080$ & Cukup \\
\hline $0,81-0,99$ & Tinggi \\
\hline 1 & Sangat tinggi \\
\hline
\end{tabular}

\section{HASIL dan PEMBAHASAN}

Keanekaragaman foraminifera bentik pada 20 sampel sedimen dapat dilihat pada Tabel 2. Dari hasil identifikasi didapatkan 66 spesies foraminifera bentik dengan 7 ordo yaitu Astrorhizida, Lituolida, Rotaliida, Spirillinida, Textulariida, dan Trocahmminida.

Jumlah individu terbanyak ditemukan pada kedalaman 11-15 m yaitu 1.380. TB-05 merupa-kan titik dengan perolehan spesies terbanyak yakni 33 spesies. Titik tersebut terletak di perairan laut dengan kadar garam $3,47 \mathrm{mg} / \mathrm{L}$, turbiditas 2,27 NTU, dan kecerahan 7,5 meter. Salinitas yang tinggi mempengaruhi proses pembentukan cangkang, sedangkan turbiditas dan kecerahan mempengaruhi besarnya intensitas cahaya yang dapat menembus suatu perairan. Sebaran dari foraminifera bentik dapat dilihat pada Gambar 1 .

lokasi lain yang memiliki jumlah spesies yang tinggi adalah TB-02, TB-03, TB-04, TB-06, dan TB-07. TB-03 dengan nilai DO sebesar $8,3 \mathrm{mg} / \mathrm{L}$. Hal ini menandakan banyaknya organisma perairan yang menghasilkan oksigen fotosintettik. Asterorotalia trispinosa merupakan jenis yang paling banyak ditemukan (1.553 individu). Hal tersebut dikarenakan sifat ketahanan dan adaptasi yang baik dimiliki oleh jenis tersebut. Dari 66 spesies, spesies yang mendominasi keseluruhan titik penelitian adalah spesies dari ordo Rotaliida. Spesies tersebut antara lain Amphistegina, $\mathrm{Am}$ monia, Asterorotalia, Rosalina, Cibrononion, Florilus, Assilina, Operculina, Cibicides, Cellanthus, Elphidium, dan Rotalia.

Dari Tabel 2 terlihat bahwa TB-11 memiliki nilai $\mathrm{K}$ dan KR tertinggi. Untuk Indeks Keanekaragaman, Indeks Kemerataan, dan Indeks dominansi tertinggi berturut-turut dimiliki oleh titik TB-05, TB01, dan TB-20 dengan nilai 3,378; 0,953; dan 0,687 . Komunitas pada keduapuluh titik penelitian tidaklah stabil. Nilai $\mathrm{H}^{\prime}$ yang didapat menunjukkan stabil tidaknya titik penelitian tersebut.

Adanya pengaruh dari berbagai faktor seperti kedalaman, kecerahan, temperatur, $\mathrm{pH}$, turbiditas, salinitas, dan DO terhadap Indeks Keanekaragaman dapat dilihat dari besarnya nilai Korelasi Pearson ( $r$ ). Nilai yang menyatakan besarnya hubungan antara $\mathrm{H}^{\prime}$ kedalaman, kecerahan, temperatur, $\mathrm{pH}$, turbiditas, salinitas dan $\mathrm{DO}$ berturutturut adalah 0,$874 ; 0,962 ; 0,962 ; 0,966 ; 0,829$; 0,966 ; dan 0,968 . Keseluruhan nilai korelasi yang didapat menunjukkan bahwa parameter kualitas air memiliki korelasi yang tinggi terhadap kestabilan komunitas pada suatu perairan. 
Tabel 2. Kelimpahan (K), Kelimpahan Relatif (KR), Indeks Keanekaragaman Jenis ( $\left.H^{\prime}\right)$, Indeks Kemerataan (E), dan Indeks Dominansi (C) Foraminifera bentik di teluk Balikpapan

\begin{tabular}{|c|c|c|c|c|c|c|}
\hline No Sampel & $\sum$ Spesies & $\sum$ Individu & $\mathrm{K}$ & $\mathbf{H}^{\prime}$ & $\mathbf{J}^{\prime}$ & $\mathrm{D}$ \\
\hline TB-01 & 4 & 8 & 0,564 & 1,386 & 0,953 & 0,047 \\
\hline TB-10 & 11 & 299 & 43,781 & 2,565 & 0,519 & 0,481 \\
\hline TB-11 & 12 & 298 & 94,576 & 2,639 & 0,617 & 0,383 \\
\hline TB-15 & 13 & 207 & 37,518 & 2,996 & 0,625 & 0,375 \\
\hline TB-18 & 2 & 9 & 1,344 & 1,099 & 0,773 & 0,228 \\
\hline TB-02 & 24 & 300 & 49,788 & 2,996 & 0,754 & 0,247 \\
\hline TB-03 & 23 & 232 & 43,713 & 3,332 & 0,826 & 0,175 \\
\hline TB-05 & 33 & 172 & 80,668 & 3,738 & 0,854 & 0,146 \\
\hline TB-06 & 24 & 260 & 46,245 & 3,178 & 0,870 & 0,130 \\
\hline TB-07 & 22 & 248 & 24,629 & 3,091 & 0,841 & 0,159 \\
\hline TB-04 & 20 & 285 & 62,752 & 3,219 & 0,749 & 0,251 \\
\hline TB-09 & 17 & 300 & 47,333 & 2,974 & 0,746 & 0,260 \\
\hline TB-12 & 15 & 262 & 16,391 & 2,890 & 0,711 & 0,289 \\
\hline TB-13 & 15 & 232 & 13,968 & 3,045 & 0,697 & 0,303 \\
\hline TB-16 & 14 & 300 & 47,034 & 3,045 & 0,614 & 0,386 \\
\hline TB-08 & 16 & 300 & 63,456 & 2,890 & 0,403 & 0,597 \\
\hline TB-20 & 12 & 288 & 27,441 & 2,708 & 0,319 & 0,687 \\
\hline TB-19 & 16 & 296 & 20,915 & 3,258 & 0,571 & 0,429 \\
\hline TB-14 & 12 & 172 & 12,022 & 2,773 & 0,616 & 0,384 \\
\hline TB-17 & 2 & 10 & 0,992 & 0,693 & 0,722 & 0,278 \\
\hline
\end{tabular}

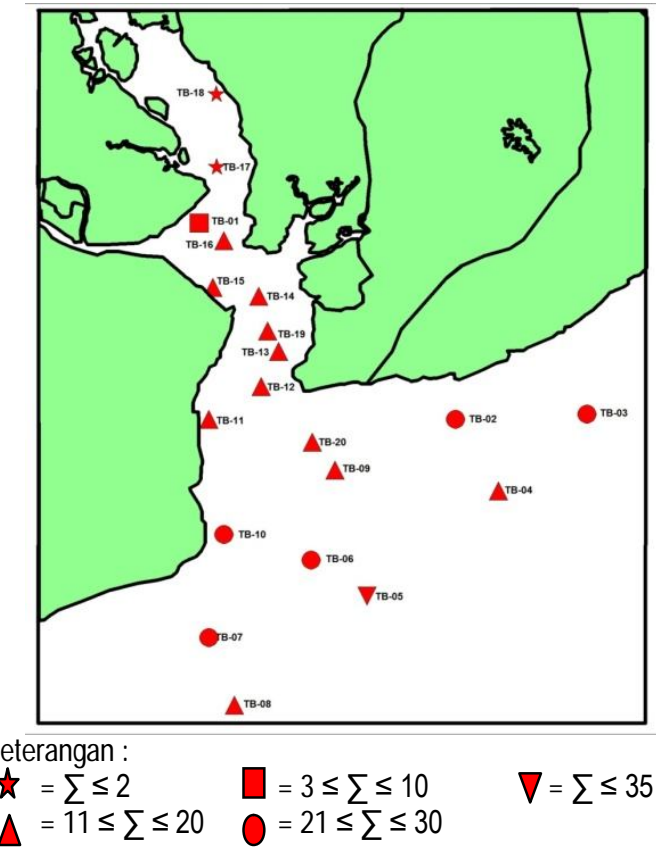

Gambar 2. Peta Sebaran Foraminifera Bentik di Perairan Teluk Balikpapan

\section{KESIMPULAN}

Dari keseluruhan Ikasi yang diteliti, TB-05 memiliki jumlah spesies terbanyak, sedangkan Asterorotalia trispinosa merupakan spesies yang paling banyak ditemukan dan mendominasi seluruh titik. Jumlah jenis dan jumlah individu tidak hanya dipengaruhi oleh kedalaman dan sedimentasi daratan, namun juga dipengaruhi oleh faktor lingkungan.

\section{UCAPAN TERIMA KASIH}

Ucapan terima kasih disampaikan kepada Kepala Pusat Penelitian dan Pengembangan Geologi Kelautan yang telah memberikan izin untuk melakukan penelitian, sehingga penelitian ini dapat berjalan dengan baik.

\section{DAFTAR PUSTAKA}

Bakus, J. G. 1990. Quantitative Ecology and Marine Biology. Departement of Biological Sciences. University of Southern California. Los Angeles.

Barker, R.W. 1960. Taxonomic Notes. Paleontologi. USA. 
Loeblich, R. dan Tappan. 1994. Foraminifera Of The Sahul Shelf and Timor Sea. Departement Of Eath and Space Sciences. University Of California. Los Angeles.

Murray. 1973. Foraminifera Bentonik dan Spesifikasinya Pada Beberapa Lingkungan Perairan Dangkal di Indonesia. Ikatan Ahli Geologi Indonesia. Jakarta.
Susmiati. 1981. Foraminifera Bentonik dan Spesifikasinya Pada Beberapa Lingkungan Perairan Dangkal di Indonesia. Ikatan Ahli Geologi Indonesia. Jakarta. 